\title{
Complex Formation of Silk Fibroin with Poly(acrylic acid)
}

\author{
Qinwei GaO, Zhengzhong SHAO, ${ }^{\dagger}$ Yuyu Sun, Heng LIN, \\ Ping ZHOU, and Tongyin YU \\ Department of Macromolecular Science and Education Ministry Key Laboratory of Molecular Engineering
of Polymers, Fudan University, Shanghai 200433, People's Republic of China
}

(Received August 23, 1999)

\begin{abstract}
Silk fibroin (SF) and poly(acrylic acid) (PAA) can interact when their aqueous solutions were mixed. Viscometric study showed that SF/PAA complex formation depended on the ratios of SF and PAA in dilute solution. SF/ PAA complexes varied from soluble state to gel and to precipitate when both concentrations of mixed solution were increased gradually. FT-IR results showed that PAA and SF were liable to form interpolymer hydrogen bonds, and SF conformation changed in the complexes. FT-IR spectra also suggested the formation and crystal perfection of PAA/SF complex crystal relied on the ratios of SF and PAA, which were confirmed by the observation of X-ray diffraction. KEY WORDS Complex / Silk Fibroin/Poly(acrylic acid)/ Hydrogen Bond /
\end{abstract}

Silk fibroin (SF) fibers from Bombyx mori silkworm have primarily been used in textile industry for thousands of years. In the past two decades, materials concerning with SF had also been utilized in the areas of biomedical and biochemical applications. ${ }^{1-3}$ Blends of $\mathrm{SF}$ with other natural or synthetic polymers, such as poly(vinyl alcohol) (PVA), ${ }^{4-6}$ chitosan, ${ }^{7}$ sodium polyglutamate, ${ }^{8}$ sodium alginate ${ }^{9}$ and cellulose ${ }^{10}$ have attracted abundant academic and practical interest. It is anticipated that such materials show new desirable properties not to be expected in conventional homopolymers. Clearly, comprehension of the details in the miscibility of SF with these polymers may provide considerable insight into the design of new materials with selected functional performances. However, there have been only few explicit studies dealing with the miscibility of SF with these polymers.

Poly(acrylic acid) (PAA) and poly(methacrylic acid) ( $P$ MAA) are widely used as polyelectrolytes. Many investigations have been performed on their complexation with other natural and synthetic polymers such as PVA, ${ }^{11}$ poly(vinylbenzyltrimethylammonium chloride) ( P V B M A), ${ }^{12}$ poly(acrylamide) (PAAm), ${ }^{13-15}$ poly(ethylene oxide) (PEO) ${ }^{16-18}$ poly(ethylene glycol) (PEG) ${ }^{19,20}$ and chitosan. ${ }^{21}$ Moreover, PAA was also used to separate proteins by precipitation of complexes of PAA and proteins. ${ }^{22,23}$ The complexation of PAA with poly(amino acids), such as poly (L-lysine) (PLL) ${ }^{24,25}$ and poly(L-proline) (PLP), ${ }^{26}$ was also invested, and interpolymer interaction between PAA and poly(amino acids) caused the conformation change of poly(amino acids).

Recently, we have been interested in various acrylic polymers and SF blends. In our previous articles, it was found that SF was immiscible with polyacrylonitrile, but was partly miscible with poly(acrylonitrile-co-methyl acrylate) (PANMA) ${ }^{27,} 28$ Because of the formation of hydrogen bonds between SF and PANMA, conformation change of SF in their blends was observed. In systems of $\mathrm{SF} /$ poly (potassium acrylic acid) (PAA-K) blend as well as $\mathrm{SF} /$ polyalanine (PALA) blend, ${ }^{29}$ the specific interaction and conformation change of SF in these blends were ob- served as well. In order to provide further evidence on the specific interactions and conformation change of SF in blends, we explored the blend of SF/PAA system in present work. SF/PAA complex forming by hydrogen bond could be detected with viscometric, FT-IR and Xray diffraction. The crystallinity and perfection of complex crystal were both dependent on SF/PAA ratios.

\section{EXPERIMENTAL}

\section{Materials}

Preparation of SF solution: Degummed SF from Bombyx mori silk fibers was dissolved in $9.3 \mathrm{~mol} \mathrm{~L}^{-1} \mathrm{LiBr}$ aqueous solution under constant stirring for several hours at room temperature. ${ }^{6}$ After dialysis against deionized water for three days, the solution was filtered. This solution was further diluted with deionized water to prepare the required concentration.

Preparation of PAA solution : PAA was synthesized according to the reference, ${ }^{30}$ and molecular weight, as determined by intrinsic viscosity from the equation, ${ }^{31}[\eta]$ $=8.5 \times 10^{-4} M^{1 / 2}$, is 35000 . Then PAA aqueous solutions of required concentration were prepared.

Preparation of dilute SF/PAA mixture solution: mixed solutions were prepared by dropwise adding required amount of $0.1 \mathrm{wt} \%$ PAA into $0.1 \mathrm{wt} \% \mathrm{SF}$ solution with slow stirring. The resultant solutions were transparent, and they were carefully stirred for at least $2 \mathrm{~h}$ and then stored for $24 \mathrm{~h}$ at room temperature before detection. $0.1 \mathrm{wt} \% \mathrm{PAA}, 0.1 \mathrm{wt} \% \mathrm{SF}$ and above mixtures were used for viscometric study, and all solutions maintained transparent during measurement.

Preparation of SF/PAA precipitates : a series of required volume of $1.4 \mathrm{wt} \%$ PAA solution were added dropwise into the given amount of $1.4 \mathrm{wt} \% \mathrm{SF}$ solution with slow stirring. Precipitates were observed at once. The resultant mixtures were carefully stirred for at least $2 \mathrm{~h}$ and then stored for $24 \mathrm{~h}$ at room temperature. The precipitates were filtrated on a glass filter, and filtrates were used to cast films. Then precipitates were immersed in deionized water for $24 \mathrm{~h}$ to wash out soluble

\footnotetext{
${ }^{\dagger}$ To whom correspondence should be addressed (Tel : +86-21-65642866, Fax : +86-21-65640293, e-mail : zzshao@fudan.edu.cn).
} 
PAA and SF, if there were any. The precipitates were airdried, then dried to constant mass in vacuo at room temperature for a week.

Solutions of $1.4 \mathrm{wt} \%$ PAA, $1.4 \mathrm{wt} \% \mathrm{SF}$ and above filtrates were used to cast films on PET plates. The films were dried like SF/PAA precipitates. All precipitates and films were stored in a desiccator under vacuum to minimize any possible adsorptive water. The SF/PAA ratios $(\mathrm{wt} / \mathrm{wt})$ of all samples in present work were assigned to the contents of SF and PAA in solutions instead of contents of SF and PAA components in precipitates.

\section{Measurement}

Precipitate yields were calculated by the equation, $y=$ $w_{\mathrm{p}} /\left(w_{\mathrm{SF}}+w_{\mathrm{PAA}}\right) \times 100 \%$, where $y$ was the precipitate yield, $w_{\mathrm{p}}$ was the weight of precipitate, $w_{\mathrm{SF}}$ and $w_{\mathrm{PAA}}$ were the weights of SF and PAA in given solution respectively.

Viscosities of dilute solutions of SF, PAA and their mixtures were determined in a conventional Ubbelodhe capillary vicometer at $25 \pm 0.1^{\circ} \mathrm{C}$. Concentration of solutions was maintained at $0.1 \mathrm{wt} \%$.

FT-IR spectra were recorded on a MANMNA IR-550 (Nicolet Corp.) spectrometer. The samples were examined in $\mathrm{KBr}$ discs. To remove adsorptive moisture, all discs were carefully dried under vacuum in a desiccator before measurement. For each spectrum, 32 scans were taken at a resolution of $4 \mathrm{~cm}^{-1}$. All spectra presented here were expanded to full scale.

X-ray diffraction measurements were performed with a Rigaku D-MAX/Rb diffractometer (Rigaku Corp.), using $\mathrm{Cu}-K_{\alpha}$ radiation $\left(\lambda=1.54 \AA\right.$ ) in the $2 \theta$ range of $5^{\circ}-50^{\circ}$ at $40 \mathrm{kv}$ and $100 \mathrm{~mA}$.

\section{RESULTS AND DISCUSSION}

\section{Viscosity : Dilute Solutions}

As for complexes of PAA with other polymers, two types of viscous behavior may be observed : a) In the systems such as PVA/PAA ${ }^{11}$ and PVBMA/PMAA, ${ }^{12}$ specific viscosity $\left(\eta_{\mathrm{sp}}\right)$ of mixed solution was greater than that of individual component, varied with PAA or PMAA content and reached to a maximum. b) In the systems such as PAAm/PAA, ${ }^{13.14}$ PEG/PAA ${ }^{19}$ PEO/PAA ${ }^{16,17}$ and chitosan/PAA, ${ }^{21} \eta_{\mathrm{sp}}$ of complex was less than that of individual polymer and had a minimum.

The curve 1 in Figure 1 shows the relationship between $\eta_{\mathrm{sp}}$ of SF/PAA mixed solution and their ratios. The value of $\eta_{\mathrm{sp}}$ increases rapidly up to around $30 \%$ PAA concent, then gradually decreases with increasing PAA. The viscous behavior in present system is similar to those in systems of PVA/PAA, ${ }^{11}$ PVBMA/PMAA $^{12}$ and $\mathrm{PEO} /$ PAA. ${ }^{18}$

In present system, the $\mathrm{pH}$ value of $0.1 \mathrm{wt} \%$ PAA solution was 3.0, where the dissociation of carboxylic groups of PAA was extremely restrained, and PAA molecules can form dimers. ${ }^{16,32}$ The $\mathrm{pH}$ value of $0.1 \mathrm{wt} \%$ SF solution was 5.0, and SF chains showed random coil/silk I form. ${ }^{33}$ The $\mathrm{pH}$ values of SF/PAA mixtures nearly kept constant (being 4.0 or so) up to $35 \%$ PAA, and then decreased with increasing PAA. As PAA is added into SF, the complexation of PAA with SF is caused by interaction between carboxylic groups of PAA and amide groups of SF. Thus the dissociation of PAA dimers is promoted, and both of PAA and SF chains are partly extended. In addition, each PAA chain may be associated with a few of $\mathrm{SF}$ chains and vice versa. Thus more PAA and SF chains interact and are extended. All these factors result in a very high viscosity of mixed solution. The increasing $\mathrm{pH}$ values of SF/PAA solutions with contents of SF suggest the concentration of free carboxylic groups be reduced by the formation of hydrogen bonds between carboxylic groups of PAA and amide groups of SF. Since $\mathrm{pH}$ maintained constant after SF beyond 65\%, excess SF did not appreciably affect PAA ionization, but it caused the decrease of viscosity. Further evidences of SF/PAA hydrogen-bonding are showed in the behaviors of concentrated SF/PAA solutions and FT-IR spectra of SF/ PAA precipitates below. The similar explanation was already applied to complexation in the systems of PMAA PAAm,${ }^{13}$ PEO/PAA and PEO/PMAA. ${ }^{16,17}$

\section{Yield of SF/PAA Precipitates : Concentrated Solutions}

For SF/PAA solutions, visual phenomena were dependent on concentrations as well as SF/PAA ratios. The mixtures of $0.1 \mathrm{wt} \% \mathrm{SF}$ and $0.1 \mathrm{wt} \%$ PAA were optically clear to naked eyes in whole range of SF/PAA ratios. After these mixed solutions were stored at room temperature for $24 \mathrm{~h}$, neither separation nor precipitation could be observed. When the concentration of both PAA and $\mathrm{SF}$ reached $0.5 \mathrm{wt} \%$, few precipitates produced as solutions being mixed, and separation or gelation could be observed after mixtures were stored for about $24 \mathrm{~h}$. Furthermore, when the concentrations of SF and PAA were both higher than $1.0 \mathrm{wt} \%$ and solutions were mixed, precipitates formed at once. In our previous work, neither separation nor precipitation could be observed in SF/ PAA-K mixture under any concentration. ${ }^{29}$ It shows that the intermolecular interaction between SF and PAA-K (mainly are electrostatic interaction) is quite different from that between SF and PAA, which suggests the formation of hydrogen bonds between carboxylic groups of PAA and amide groups of SF. As in complex systems of PMAA/PAAm, ${ }^{13}$ PEO/PAA and PEO/PMAA, ${ }^{16,17}$ each PAA chain can also interact with several SF chains and vice versa in SF/PAA solutions. The concentrated SF/ PAA solution turns into a network-like structure similar to a physical gel, and eventually the precipitation of SF/ PAA is caused with increasing solution concentrations.

The influence of the ratios of SF and PAA on the precipitate yield is shown in Figure 1 (curve 2). The precipitate yield is the highest at about $38 \%$ PAA. This PAA content is more than that of the highest $\eta_{\mathrm{sp}}$ in dilute solutions. After precipitates were removed, filtrates were stored at room temperature for more than $24 \mathrm{~h}$ to observe their visual changes. Whole filtrate of sample 75/ 25 (SF/PAA) gelated, a few precipitates appeared in the filtrate of sample 65/35 (SF/PAA), but no gel or precipitate could be observed in filtrates as the ratio of $\mathrm{SF}$ and PAA less than 65/35 even after a week. Therefore, in concentrated SF/PAA solutions, a few of interacted SF and PAA chains may be soluble in mixture solutions with higher SF concent, and they would gradually gelate or precipitate afterwards in filtrates. The presence of intermolecular interaction between SF and PAA chains in filtrates is also confirmed by FT-IR spectra of SF-PAA 


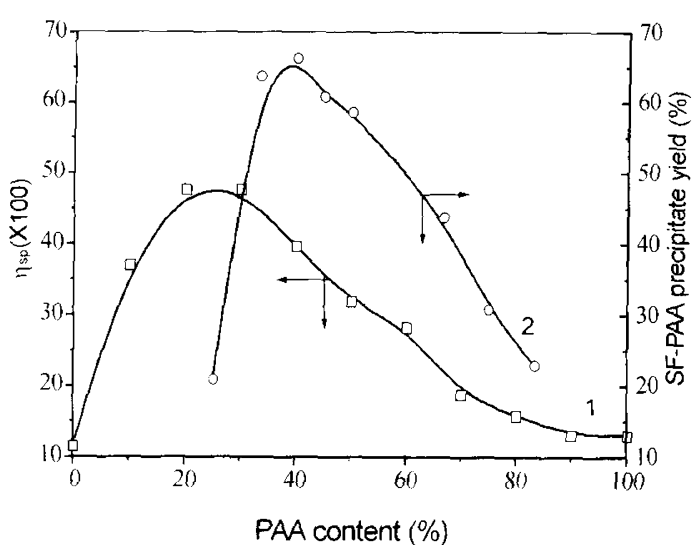

Figure 1. The relation of the $\eta_{\mathrm{sp}}$ of SF/PAA mixtures and yields of SF/PAA precipitates to the PAA contents.

filtrates given in Figure 2. Soluble complexes were observed in PAA/PVA system, ${ }^{11}$ concentrated PEO/PAA mixtures ${ }^{16,17}$ as well as in the polyion/protein system of sodium poly(vinyl sulfate) (PVS)/Bovine serum albumin (BSA) ${ }^{34}$ Since the soluble interacted SF and PAA chains are present in solutions with higher SF content, the highest precipitate yield is obtained in the mixed solution with a relative higher PAA content (Figure 1).

\section{FT-IR Study}

As well known, FT-IR is a very useful tool for detecting the interaction in polymer blends. Figure 2 shows FT-IR spectra of SF/PAA filtrates after the SF/PAA precipitates being removed from mixture solutions. The spectrum of the filtrate film $(\mathrm{SF} / \mathrm{PAA}=25 / 75)$ is consistent with that of neat PAA, suggesting that there is no $\mathrm{SF}$ in the filtrate. In another word, SF is completely separated from mixed solution to PAA/SF precipitate in the presence of excess PAA. However, the spectrum of the filtrate film $(\mathrm{SF} / \mathrm{PAA}=75 / 25)$ is apparently different with that of neat SF. The shoulder at $1740 \mathrm{~cm}^{-1}$ due to the $\mathrm{C}=\mathrm{O}$ group of PAA ${ }^{20,39}$ shows the existence of PAA in the filtrate, while the new band at $1630 \mathrm{~cm}^{-1} 33,35-38$ due to amide II of SF indicates conformation change of $\mathrm{SF}$ caused by interaction between SF and PAA. That is to say, it may suggest that there be SF/PAA complexation in the filtrates, and SF/PAA precipitates be caused by SF/PAA complexation. Conformation change due to SF/PAA complexation will be discussed in detail in FTIR study below.

In present study, it is found that FT-IR spectrum of film cast from dilute SF/PAA solution is similar to that of precipitate from concentrated SF/PAA sample in the same SF/PAA ratio, which indicate that same interaction exists in both. In order to lessen the influence of unassociated SF and/or PAA in mixture solutions shown in Figure 2, SF/PAA precipitates are used to study with FT-IR (and X-ray diffraction).

Figure 3 shows the FT-IR spectra in region 2800 $3800 \mathrm{~cm}^{-1}$ of SF, PAA, and SF/PAA precipitates. For SF, the band at $3300 \mathrm{~cm}^{-1}$ due to hydrogen-bonded $\mathrm{N}-\mathrm{H}$ stretching vibration in crystal phase suggests minor oriented regions in amorphous regenerated SF ${ }^{33,35-38} \mathrm{As}$ to PAA, the band centered at $3200 \mathrm{~cm}^{-1}$ is due to the hydrogen-bonded $\mathrm{O}-\mathrm{H}$ stretching vibration in PAA dimers. ${ }^{20,39}$

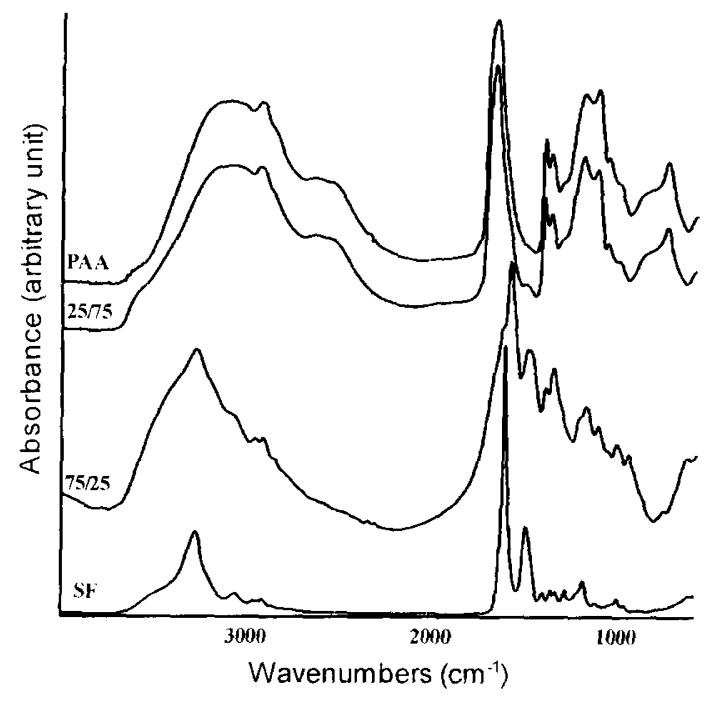

Figure 2. FT-IR spectra of SF, PAA, and the filtrates of SF/PAA mixtures.

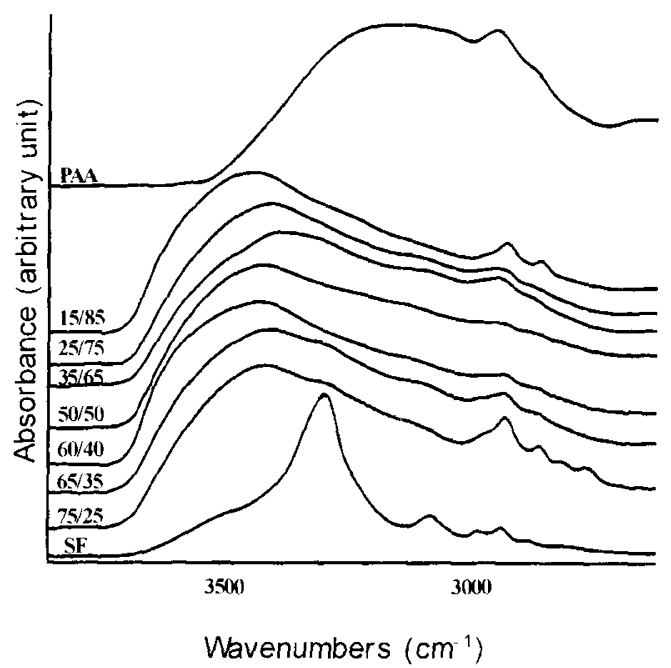

Figure 3. FT-IR spectra in the $\mathrm{N}-\mathrm{H}$ stretching region for $\mathrm{SF}$, PAA, and SF/PAA complexes.

After PAA mixing with SF, a new band centered at $3440 \mathrm{~cm}^{-1}$ occurs in the spectra of precipitates. This band could be assigned to free $\mathrm{N}-\mathrm{H}$ (unhydrogen-bonded) and free $\mathrm{O}-\mathrm{H}$ of $\mathrm{SF},{ }^{33}$ free $\mathrm{O}-\mathrm{H}$ groups of PAA and/ or their cooperation. On the other hand, the $\mathrm{N}-\mathrm{H}$ band at $3300 \mathrm{~cm}^{-1}$ is gradually weakened and screened by broadened $3440 \mathrm{~cm}^{-1}$ band with the increase of PAA, meaning the breaking of intramolecular and intermolecular hydrogen bonds of SF. Meanwhile, the $\mathrm{O}-\mathrm{H}$ band of PAA at $3200 \mathrm{~cm}^{-1}$ is pronouncedly weakened so as not to be detected, suggesting the dissociation of PAA dimers or single chain structure of PAA in precipitates. The broad band at $3440 \mathrm{~cm}^{-1}$ may primarily indicate a broad distribution of local environments of amide groups and/or an appreciable concentration of free $\mathrm{O}-\mathrm{H}$ groups of PAA and $\mathrm{N}-\mathrm{H}$ groups of SF. It is difficult to distinct the contribution of $\mathrm{O}-\mathrm{H}$ groups in PAA from that of $\mathrm{N}-\mathrm{H}$ and $\mathrm{O}-\mathrm{H}$ groups in SF. This result is quite different from that in SF/PAA-K system. ${ }^{29}$ In SF/PAA-K system with two kinds of interpolymer interactions, i.e., hydrogenbonding and electrostatic interaction, the hydrogen 
bonded $\mathrm{N}-\mathrm{H}$ band was greatly broadened and gradually shifted to higher frequency with increasing PAA-K, while the free $\mathrm{N}-\mathrm{H}$ band could hardly be detected. All above evidences show that the interpolymer interaction between PAA and SF is mainly caused by hydrogen bonds. The viscous behavior of SF/PAA mixture considered, the complexation of PAA with SF probably destroys intramolecular and intermolecular hydrogen bonds in minor oriented domains of SF, and induced the conformation change of $\mathrm{SF}$, as well as dissociation of PAA dimer.

As for SF, the bands at $1660 \mathrm{~cm}^{-1}, 1540 \mathrm{~cm}^{-1}$ and $1235 \mathrm{~cm}^{-1}$ are assigned to amide I, amide II and amide III of random coil/silk I form respectively, while the bands at $1630 \mathrm{~cm}^{-1}, 1535 \mathrm{~cm}^{-1}$, and $1265 \mathrm{~cm}^{-1}$ are assigned to amide I, amide II, and amide III of $\beta$-form/silk II form ${ }^{33,35-38,40}$ respectively. The difference spectra in these regions are obtained by subtracting the spectrum of neat PAA from the spectra of complexes, and they present the sum of SF contribution to the complexes as well as any change due to interaction between SF and PAA.

Figure 4 gives the difference spectra of complexes and $\mathrm{SF}$ spectrum in amide I region mainly attributed to the $\mathrm{C}=\mathrm{O}$ stretching vibration. ${ }^{33,35-38,40}$ As for SF, there is only one band at $1655 \mathrm{~cm}^{-1}$ due to random coil/silk form. With the addition of PAA, a new band at $1616 \mathrm{~cm}^{-1}$ due to the $\beta$-form of SF appears in complex spectra, suggesting the structural transformation of blends be caused by the formation of SF/PAA complexes. The $1616 \mathrm{~cm}^{-1}$ band shifts to higher frequency and its intensity increases with increasing PAA. On the other hand, the band at $1658 \mathrm{~cm}^{-1}$ shifts to $1662 \mathrm{~cm}^{-1}$ with addition of PAA, and then shifts to lower frequency after SF/PAA beyond 75/25 at expense of intensity. The two bands gradually overlap and combine into one peak at 1645 $\mathrm{cm}^{-1}$.

In the previous articles, ${ }^{28,29}$ we suggested that many groups of SF can form specific interaction with other polymers, and the restriction of conformation of SF may play an important role in the formation of the specific interaction. Consequently results from FT-IR spectra may be comprehensive effect of many kinds of possible specific interaction. Since complexation of SF with PAA is mainly caused by hydrogen-bonding between carboxylic groups of PAA and amide groups of SF, it is possible that the band $1616 \mathrm{~cm}^{-1}$ may result from comprehensive hydrogen bonds. Additionally, the frequency of $1616 \mathrm{~cm}^{-1}$ band is lower than that of the $\beta$-form in neat SF and its intensity increases with PAA increase. The existence of $1655 \mathrm{~cm}^{-1}$ band suggests that only partial amide groups of SF be involved in the hydrogen bonds. All these facts can result from the stronger hydrogen bonds between $\mathrm{O}^{-}$ $\mathrm{H}$ groups of $\mathrm{PAA}$ and $\mathrm{C}=\mathrm{O}$ groups of $\mathrm{SF}$ in complexes as well as hydrogen bonds in SF itself. Compared with plain SF, SF/PAA complexes only perform an imperfect $\beta$-form-like structure. The increase of PAA could decrease the crystallinity and perfection of crystal of complexes because of the formation of amorphous PAA domains, which would increase the frequency of bands and decrease the intensity of bands. In addition, under the restriction of $\beta$-conformation of SF, although most interpolymer hydrogen bonds are straight in complexes, there may be a number of interpolymer bent hydrogen bonds,

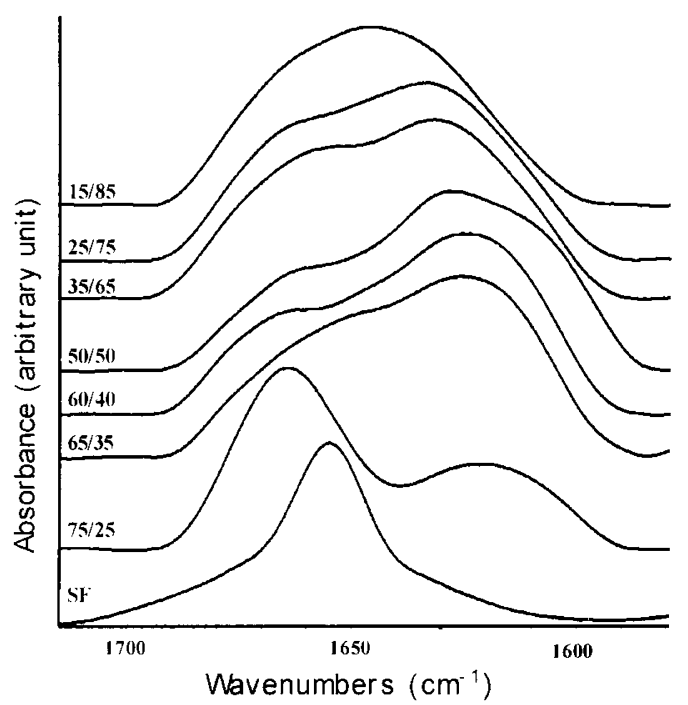

Figure 4. FT-IR spectra in the amide I region for SF and SF/ PAA complexes. The spectra of complexes are difference spectra (see the text).

which would also cause a shift to higher frequency. ${ }^{41}$ Comprehensive effects of all factors mentioned above may answer for the doublet bands in amide I region.

The difference spectra of PAA/SF complexes in amide II region are shown in Figure 5. Amide II is mainly attributed to a coupled mode involving $\mathrm{N}-\mathrm{H}$ deformation vibration and $\mathrm{C}-\mathrm{N}$ stretch vibration. ${ }^{33,35-38,40}$ For SF, the band at $1545 \mathrm{~cm}^{-1}$ and the shoulder at $1520 \mathrm{~cm}^{-1}$ are due to the random coil/silk I form and the silk II form respectively. When SF/PAA is higher than $65 / 35$, the band at $1545 \mathrm{~cm}^{-1}$ shifts to higher frequency and is apparently weakened with PAA increase, while the band at $1520 \mathrm{~cm}^{-1}$ shifts to lower frequency with the increase of intensity. When the ratio of SF and PAA is lower than $65 / 35$, the band at $1545 \mathrm{~cm}^{-1}$ shifts to lower frequency and is weakened with PAA increase, while the band at $1520 \mathrm{~cm}^{-1}$ shifts to higher frequency and is still strengthened.

Figure 6 shows the spectra in amide III region which is attributed to $\mathrm{N}-\mathrm{H}$ in-plane deformation vibration and C-N stretching vibration. ${ }^{33,35-38,40}$ For SF, the band at $1240 \mathrm{~cm}^{-1}$ and the very weak band at $1270 \mathrm{~cm}^{-1}$ are due to random coil/silk I-form and $\beta$-form respectively. With the addition of PAA, the $1240 \mathrm{~cm}^{-1}$ band shifts to lower frequency and is broadened, reaching the lowest frequency $1226 \mathrm{~cm}^{-1}$ in samples $65 / 35$ and $60 / 40$, while $1270 \mathrm{~cm}^{-1}$ band shifted to lower frequency and its intensity increases with PAA. Comprehensive effects of all factors discussed in amide I region may also result in the appearance of doublet bands in amide II and amide III. The changes in these bands also suggest the structural transformation of SF and PAA in complexes caused by hydrogen-bonding.

The difference spectra in carboxyl vibration region are obtained by subtracting the spectrum of neat SF from the spectra of complexes, and they present the sum of PAA contribution to the complexes as well as any change due to interaction between SF and PAA. In Figure 7, the broad PAA carboxyl band ranging from $1700 \mathrm{~cm}^{-1}$ to $1740 \mathrm{~cm}^{-1}$ shows the coexistence of the dimeric structure with hydrogen bonds (at $1700 \mathrm{~cm}^{-1}$ ) and the mono- 


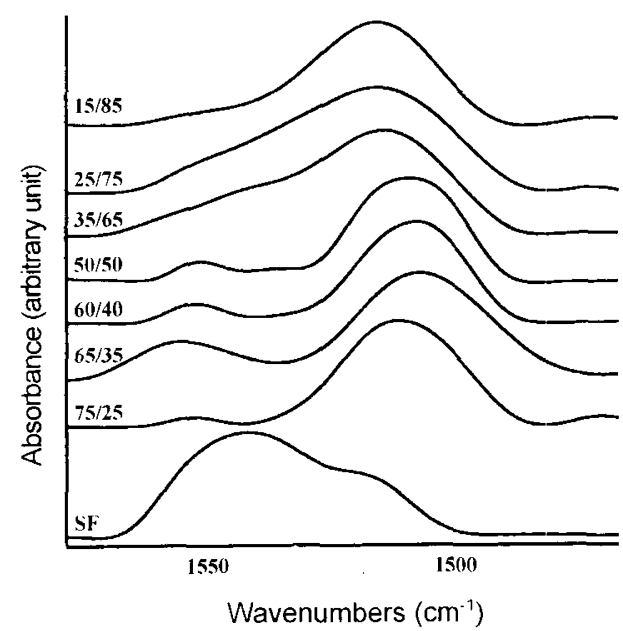

Figure 5. FT-IR spectra in the amide II region for SF and SF/ PAA complexes. The spectra of complexes are difference spectra (see the text).

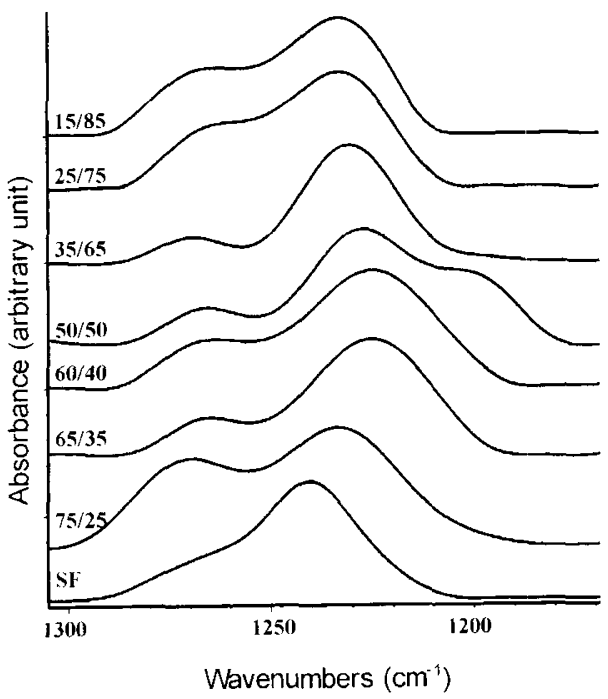

Figure 6. FT-IR spectra in the amide III region for SF and SF/ PAA complexes. The spectra of complexes are difference spectra (see the text).

meric state without hydrogen bonds (at 1740 $\left.\mathrm{cm}^{-1}\right) .20,30,39,43-45$ When PAA mixing with SF, the 1700 $\mathrm{cm}^{-1}$ band disappears entirely, indicating an exchange of hydrogen bonds from PAA dimers to carboxylic group / amide group in complexes. Moreover, the band at 1740 $\mathrm{cm}^{-1}$ slightly shifts to higher frequency with the increase of SF, showing that hydrogen-bonding between $\mathrm{N}-\mathrm{H}$ groups of $\mathrm{SF}$ and $\mathrm{C}=\mathrm{O}$ groups of PAA is very weak. In consideration of the results shown in amide $I$, amide II and amide III regions, the complexation of SF with PAA can mainly be caused by hydrogen bonds between $\mathrm{C}$ $=\mathrm{O}$ groups of $\mathrm{SF}$ and $\mathrm{O}-\mathrm{H}$ groups of PAA. Thus only partial $\mathrm{N}-\mathrm{H}$ groups of SF and $\mathrm{O}-\mathrm{H}$ groups of PAA are involved in hydrogen-bonding in SF/PAA complexes, which leads to the appearance of free $\mathrm{N}-\mathrm{H}$ band and/or free $\mathrm{O}^{-} \mathrm{H}$ band of PAA at $3440 \mathrm{~cm}^{-1}$.

\section{$X$-Ray Diffraction}

In order to confirm the above interpretation, X-ray diffraction patterns of SF, PAA and complexes are displayed in Figure 8. As to SF, there are three weak peaks

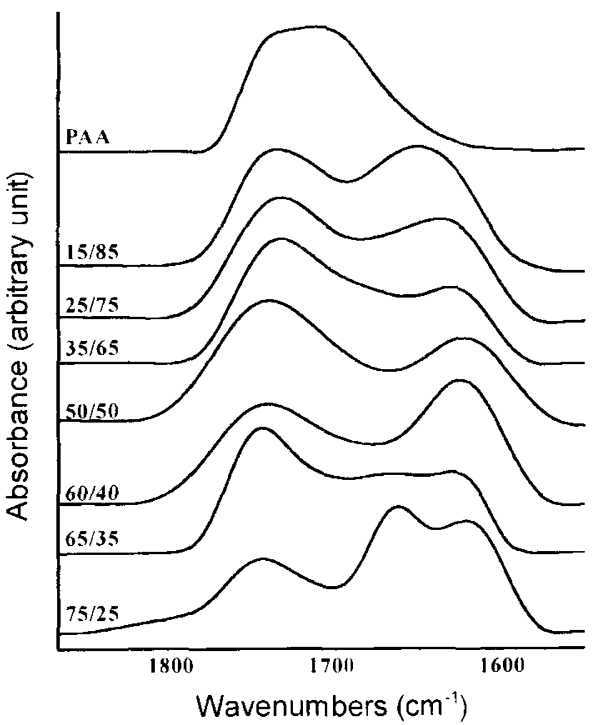

Figure 7. FT-IR spectra in $\mathrm{C}=\mathrm{O}$ group region for $\mathrm{PAA}$ and $\mathrm{SF} /$ PAA complexes. The spectra of complexes are difference spectra (see the text).

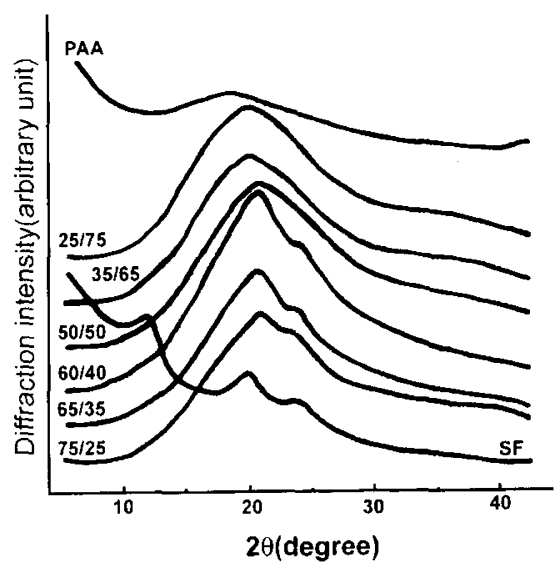

Figure 8. X-ray diffraction patterns of SF, PAA and SF/PAA complexes.

at 7.6, 4.54 and $3.73 \AA$ indicating random coil and/or silk I form. ${ }^{42}$ The curve of PAA does not show any characteristic crystalline peak, indicating that PAA is amorphous. With addition of PAA in SF, two peaks can be observed : 4.34 and $3.77 \AA$, assigned to $\beta$-sheet form of $\mathrm{SF},{ }^{42,46-48}$ which suggests that interpolymer hydrogen-bonding between SF and PAA be introduced and structural transformation occur. The intensity and width of halo reaches the strongest and the narrowest respectively at SF/PAA being $60 / 40$. It is well known that the width of X-ray diffraction peak is related to the size of crystallite. ${ }^{9,36}$ The broadened peak usually results from small crystallites, while the narrowed peak from large crystallites. Peaks at smaller angle, corresponding to larger spacing, mean the decrease of the crystalline perfection. Sample 60/40 (SF/PAA) shows the least spacing $4.34 \AA$ and strongest intensity, indicating the best perfection of crystal. When SF/PAA is less than $60 / 40$, the peak $3.77 \AA$ disappears, meanwhile the peak $4.34 \AA$ is broadened and shifts to lower angle. Perhaps the excess PAA forms amorphous domains itself in complexes so that the perfection of complex crystal is lessened. The diffraction patterns sug- 
gest the effect of PAA/SF ratios on the structure transformation of complexes.

\section{CONCLUSION}

Overall, in present SF/PAA system, both $\eta_{\text {sp }}$ and precipitate yield show that the complexation between PAA and SF relies on SF and PAA concentrations and their ratios. FT-IR spectra show SF/PAA complexation can induce the dissociation of PAA dimers, damage of minor oriented regions in $\mathrm{SF}$, and conformation changes of $\mathrm{SF}$ and PAA in complexes. As for PAA in complex, both hydrogen-bonded $\mathrm{O}-\mathrm{H}$ band and hydrogen-bonded $\mathrm{C}=\mathrm{O}$ band in dimers disappear, while both free $\mathrm{O}-\mathrm{H}$ and free $\mathrm{C}=\mathrm{O}$ band in monomeric state appear. As for $\mathrm{SF}$, the band due to hydrogen-bonded $\mathrm{N}-\mathrm{H}$ is weakened, while free $\mathrm{N}-\mathrm{H}$ band appears. The conformation change of complex results in the doublet bands due to random coil and $\beta$-form in FT-IR spectra respectively. X-ray diffraction study provides further evidence of the changes of SF conformation, crystallinity and crystal perfection of complexes.

The results of these methods coincide well. It is shown that SF and PAA can form complexes when their aqueous solutions are mixed. The complexation between SF and PAA may be hydrogen-bonding between $\mathrm{C}=\mathrm{O}$ of $\mathrm{SF}$ and $\mathrm{O}-\mathrm{H}$ of PAA. Moreover, the structure, crystallinity and perfection of crystal of complexes are all dependent on the ratios of SF and PAA, which suggested a useful method to prepare semicrystalline SF membrane for immobilizing material of enzymes.

Acknowledgment. The authors thank for the financial support by the National Science Foundation of China (No.59603005).

\section{REFERENCES}

1. A. Kuzuhara, T. Asakura, R. Tomoda, and T. J. Matsunaga, J. Biotechnol., 5, 199 (1987).

2. M. Demura and T. Asakura, Biotechnol. Bioeng., 33, 598 (1989).

3. T. Yu, H. Liu, J. Deng, and Y. Liu, J. Appl. Polym. Sci., 58, 973 (1995).

4. K. Yamaura, M. Kuranuki, M. Suzuki, T. Tanigami, and S. Matsuzawa, J. Appl. Polym. Sci., 41, 2409 (1990).

5. M. Isukada, G. Freddi, and J. S. Crighton, J. Polym. Sci. Phys. Ed., 32, 243 (1994).

6. Y. Liu, H. Liu, J. Qian, J. Deng, and T. Yu, J. Macro. Sci. Pure. Appl. Chem., A33, 209 (1996).

7. C. X. Liang and K. Hirabayashi, Sen-i Gakkaishi, 47, 334 (1991).

8. C. X. Liang and K. Hirabayashi, Sen-i Gakkaishi, 47, 535 (1990).

9. C. X. Liang and K. Hirabayashi, J. Appl. polym. Sci., 45, 1937 (1992).

10. G. Freddi, M. Romano, M. R. Massafra, and M. Tsukada, $J$. Appl. polym. Sci., 56, 1537 (1995).

11. T. V. Budtova, I. E. Suleimenov, and S. Ya. Frenkel, J. Polym. Sci., Polym. Chem. Ed., 32, 281 (1994).
12. E. Tsuchida and Y. Osada, J. Polym. Sci., Polym. Chem. Ed., 14, 767 (1976).

13. V. Yu. Baranocsky, L. A. Kazarin, A. A. Litmanovich, and I. M. Papisov, Eur. Polym. J., 12, 191 (1984).

14. G. Staikos and C. Tsitsilianis, J. Appl. Polym. Sci., 42, 867 (1991).

15. M. A. Moharram, M. A. Soliman, and H. M. EL-Gendy, $J$. Appl. Polym. Sci., 68, 2049 (1998)

16. T. Ikawa, K. Abe, K. Honda, and E. Tsuchida, J. Polym. Sci., Polym. Chem. Ed., 13, 1505 (1975).

17. I. Lliopoulos and R. Audebert, Macromolecules, 24, 2566 (1991).

18. F. E. Bailey, J. R., R. D. Lundberg, and R. W. Callard, J. Polym. Sci., Part A: 2, 845 (1964).

19. T. Ptrova, I. Rashikov, V. Baranocsky, and G.Borisov, Eur. Polym. J., 27, 189 (1991).

20. X. Liu and R. A. Weiss, Macromolecules, 28, 3022 (1995).

21. H. Wang, W. J. Li, Y. H. Lu, Z. L. Wang, and W. Zhong, J. Appl. Polym. Sci., 61, 2221 (1996)

22. M. Sternberg and D. Hershbergeer, Biochim. Biophys. Acta., 342, 195 (1974).

23. A. G. Bozzano and C. E. Glatz, J. Membr. Sci., 55, 181 (1991).

24. K. Shinoda, T. Hayashi, T. Yoshida, K.Sakai, and A. Nakajima, Polym. J., 8, 202 (1976).

25. T. Kawai and A. Fujie, J. Macro. Sci., B 17, 653 (1980).

26. H. D. Kim, S. H. Jin, S. B. Lee, and J. S. Yang, Polym. Bull., 39, 45 (1997).

27. Y. Sun, Z. Shao, M. Ma, P. Hu, Y. Liu, and T. Yu, J. Appl. Polym. Sci., 65, 959(1997).

28. Y. Sun, Z. Shao, P. Hu, and T. Yu, J. Polym. Sci., Polym. Phys. Ed., 35, 1405 (1997)

29. Z. Shao, Y. Sun, P. Zhou, and T. Yu, Polym. J., 31, 470 (1999).

30. A. Einsberg, T. Yokoyama, and E. Sambalido, J. Polym. Sci., Part A-1 : 7, 1717 (1969).

31. S. Newman, W. R. Kribbaum, C. Laubier, and P, J. Flory, J. Polym. Sci., 14, 451 (1954).

32. A. Katchalaky and H. Eisenberg, J. Polym. Sci., 6, 145 (1951).

33. J. Magoshi and Y. Magoshi, J. Polym. Sci., Polym. Phys. Ed., 15, 1675 (1977)

34. J. M. Park, B. B. Muhoberac, P. L. Dubin, and J. Xia, Macromolecules, 25, 290 (1992).

35. S. Gogolewski and A. J. Pennings, Polymer, 18, 647 (1977).

36. M. Asai, M. Tsuboi, T. Shimanouchi, and S. Mizushima, $J$. Phys. Chem., 59, 322 (1955).

37. X. Liu and R. A. Weiss, J. Polym. Sci., Polym. Phys. Ed., 34, $1795(1996)$

38. D. J. Skrovanek, S. E. Howe, P. C. Painter, and M. M. Coleman, Macromolecules, 18, 1676 (1985).

39. M. M. Davies and G. B. B. M. Sutherland, J. Chem. Phys., 6, 755(1938).

40. T. Asakura, A. Kuzuhara, R. Tabeta, and H. Saito, Macromolecules, 18, 1841 (1985).

41. K. Nakamoto, M. Margoses, and R. E. Rundle, J. Am. Chem. Soc., 77, 6480(1955).

42. N. V. Bhat and S. M. Ahirrao, J. Polym. Sci., Polym. Chem. $E d ., 21,1273(1983)$

43. Y. Lee, P. C. Painter, and M. M. Coleman, Macromolecules, 21, 346 (1988).

44. J. Y. Lee, P. C. Painter, and M. M. Coleman, Macromolecules, 21, 954 (1988).

45. S. Nishi and T. Kotaka, Macromolecules, 18, 1519 (1985).

46. N. Minuoura, M. Tsukada, and M. Nagura, Polymer, 31, 265 (1990).

47. J. Magoshi and Y. Magoshi, J. Polym. Sci., Polym. Phys. Ed., 19,185 (1981).

48. J. Magoshi and Y. Magoshi, J. Polym. Sci., Polym. Phys. Ed., 17, 515 (1979). 